\title{
Graves' exophthalmos: Volumetric assessment of orbital expansion
}

\author{
Ramon S Grover MD FRCSC ${ }^{1}$, James Mainprize $\mathrm{PhD}^{2}$, \\ Edsel Ing MD FRCSC ${ }^{3}$, Oleh M Antonyshyn MD FRCSC
}

\begin{abstract}
RS Grover, J Mainprize, E Ing, OM Antonyshyn. Graves' exophthalmos: Volumetric assessment of orbital expansion. Can J Plast Surg 2003;11(4):191-197.
\end{abstract}

INTRODUCTION: Graves' ophthalmopathy is characterized by an increase in the volume of orbital soft tissue contents and an associated increase in intraorbital pressure. Surgical expansion of bony orbital volume is therefore an effective method of treating moderate to severe exophthalmos. Numerous correlations between specific decompression procedures and reduction of proptosis have been made. The main emphasis of the majority of these studies, however, appears to be of a qualitative nature rather than quantitative.

OBJECTIVES: To quantitatively examine the consequences of surgical orbital decompression in the treatment of severe Graves' exophthalmos, with respect to changes in ocular globe projection and orbital soft tissue and bony volume.

MATERIAL AND METHODS: A series of three patients (five orbits) with severe exophthalmos were evaluated. All patients were operated on by a single surgeon using a standard technique of orbitozygmatic osteotomy in conjunction with three-wall orbital decompression and release of periorbita. Data obtained from standardized preoperative and three-month postoperative computed tomography scans were transferred to an offline computer workstation. Scalar and volumetric parameters were quantitatively analyzed to determine changes in globe projection in relation to intraorbital volume differences.

RESULTS: Following surgery, mean globe retrodisplacement from the lateral orbital rim and from the optic foramen were $6.7 \mathrm{~mm}$ and $3.3 \mathrm{~mm}$, respectively. Osteotomy and decompression were effective in producing an $18.6 \%$ increase in bony orbital volume. However, the volume of intraorbital soft tissues increased substantially following surgery, with a $23.4 \%$ increase in orbital fat volume and a $12.2 \%$ increase in neurovascular tissue volume.

CONCLUSIONS: The degree of globe retrodisplacement achieved by surgical expansion of the bony orbital cavity in patients with Graves' ophthalmopathy may be less than anticipated, due to a postoperative increase in the intraorbital soft tissue volumes.

\section{Exophtalmie de Graves : évaluation volumétrique de l'expansion de l'orbite.}

INTRODUCTION : L'ophtalmopathie de Graves se caractérise par une
augmentation de volume des tissus mous dans l'orbite et est associée à une
augmentation de la pression intra-orbitale. L'expansion chirurgicale du
volume osseux de l'orbite s'avère donc un moyen efficace de traiter
l'exophtalmie modérée ou grave. De nombreuses corrélations ont été
établies entre certaines techniques de décompression et la diminution de
l'exophtalmie. Toutefois, dans la plupart des études, l'accent semble mis
sur des critères qualitatifs plutôt que quantitatifs. OBJECTIF : Quantifier les effets de la décompression chirurgicale de l'orbite dans les cas d'exophtalmie marquée de Graves quant à la position du globe oculaire et au volume de tissu dur et de tissus mous dans l'orbite. MÉTHODE : Nous avons évalué trois patients (cinq orbites) atteints d'exophtalmie marquée. Tous ont été opérés par le même chirurgien, qui a procédé à une ostéotomie orbito-zygomatique classique, associée à une décompression triple des parois de l'orbite et au dégagement du périoste orbitaire. Des données obtenues par tomodensitométrie avant l'opération et trois mois après celle-ci ont été transférées dans un poste de travail autonome. Nous avons effectué une analyse quantitative de certains paramètres volumiques et scalaires pour déterminer les variations de position du globe oculaire en fonction des différences de volume intra-orbital. RÉSULTATS : Après l'opération, la rétro-redressement moyen du globe oculaire depuis le bord latéral de l'orbite et le foramen optique a été de $6,7 \mathrm{~mm}$ et de 3,3 $\mathrm{mm}$ respectivement. L'ostéotomie et la décompression ont permis une augmentation de 18,6 \% du volume osseux de l'orbite. Toutefois, le volume intra-orbital de tissus mous a augmenté considérablement après l'intervention, soit une augmentation de $23,4 \%$ du volume de tissu adipeux et de $12,2 \%$ du volume de tissu neuro-vasculaire. CONCLUSION : Le degré de rétro-redressement du globe oculaire produit par la chirurgie d'expansion de la cavité orbitale osseuse dans les cas d'ophtalmopathie de Graves peut être moins important que prévu en raison de l'augmentation de volume des tissus mous intra-orbitaux en phase postopératoire.

\section{Key Words: Exophthalmos; Graves' disease; Orbital expansion}

T he ophthalmopathy associated with Graves' disease was first described in 1835 by an Irish physician, Robert J Graves. Its pathogenesis, however, remains uncertain. It is currently thought to be characterized by a chronic autoimmune process resulting in an infiltrative fibroblastic reaction involving all the periorbital soft tissues of both orbits. A commonly accepted hypothesis is that $\mathrm{T}$ cell lymphocytes

react against thyroid follicular cells with shared antigenic epitopes in the retro-orbital space, initiating an inflammatory cytokine release (1). This in turn stimulates the synthesis of hydrophilic glycosaminoglycans (hyaluronic acid) by retroorbital fibroblasts, and triggers the recruitment of new adipocytes from orbital adipose precursor cells. Ultimately, orbital soft tissue volume and osmotic load increase, leading to

${ }^{1}$ Craniofacial Surgery - Division of Plastic Surgery, Department of Surgery; ${ }^{2}$ Imaging Research; ${ }^{3}$ Department of Ophthalmology, Sunnybrook Health Sciences Centre, University of Toronto, Toronto, Ontario

Correspondence and reprints: Dr Ramon S Grover, Department of Surgery, Sunnybrook Health Sciences Centre, University of Toronto,

2075 Bayview Avenue, Toronto, Ontario M4N 3M5. Telephone 416-480-4868, fax 416-480-6800, e-mail rgroverca@yahoo.ca 
edema and fibrosis of involved tissues (2). The nature of the primary antigen(s) that is recognized by immunocompetent cells and autoantibodies has not been definitively determined. Potential antigens include the thyroid-stimulating hormone receptor protein and various extraocular muscle antigens (3).

The ocular manifestations of Graves' ophthalmopathy are variable, and occur concurrently with hyperthyroidism only $40 \%$ of the time. In fact, $20 \%$ of individuals with ophthalmopathy are noted to be euthyroid at time of presentation (4). Physical findings have been classified as infiltrative and noninfiltrative. The infiltrative changes are characterized by a lymphocytic infiltration of retro-orbital tissue and typically result in proptosis, extraocular muscle dysfunction and subsequent diplopia. In advanced cases, glaucoma from decreased episcleral venous outflow, or blindness secondary to compression neuropathy of the optic nerve may develop. The noninfiltrative changes are due to sympathetic hypertonia leading to spastic retraction of the eyelids, increase in palpebral fissure height, and subsequent risk of exposure keratopathy. These manifestations typically occur within 18 months of developing thyroid dysfunction. However, they may also precede or coincide with the systemic complications of dysthyroidism (5).

The treatment of Graves' ophthalmopathy primarily consists of nonsurgical therapy in the form of medications, such as steroids or immunosuppressants, or in selected cases, radiotherapy. Surgical therapy, often via multiple-staged procedures, is reserved for a minority $(5 \%)$ of patients with severe exophthalmos. Indications for surgery may be cosmetic (ie, proptosis refractory to medical treatment) or functional. Functional indications for decompression include decreasing visual acuity, visual field defects, abnormal visual-evoked potentials, disc edema, as well as corneal exposure with keratitis refractory to medical management. In severe cases, the different aspects of Graves' ophthalmopathy can be addressed by a combination of surgical techniques, including methods aimed at decreasing the soft tissue contents of the orbits or expanding the orbital bony volume. These include orbital lipectomy, two- and three-wall orbitotomies, and orbitozygomatic osteotomies (6-10). Ancillary measures such as lateral tarsorrhaphy and lid lengthening procedures are also often employed to decrease the risk of corneal exposure $(11,12)$.

To date, few studies have quantitatively examined the physical consequences of bony orbital expansion with respect to changes in ocular globe projection, and changes in the volume and distribution of orbital soft tissue contents. The present study is an initial investigation of the volumetric and morphological consequences of orbital osteotomy and expansion in patients with severe Graves' exophthalmos.

\section{PATIENTS AND METHODS}

\section{Patient series}

Since July 2002, three patients (five orbits) with severe Graves' ophthalmopathy (exophthalmos greater than $20 \mathrm{~mm}$; Werner's grade II or higher) (13) were treated at the Sunnybrook and Women's College Health Sciences Centre, by orbital osteotomy and surgical decompression of the orbits. The patients ages ranged from 40 to 54 years. There were two men and one woman. One patient presented with profound unilateral proptosis, while the remaining two had bilateral exophthalmos. One patient received steroids during the acute inflammatory phase of the disease, while one was treated with a short course of orbital radiotherapy. Two patients were active smokers. No patients had previous surgery.

\section{Clinical assessment}

All patients had a complete endocrinological and ophthalmological assessment preoperatively, and were noted to have stable nonprogressive ophthalmopathy for at least 12 months before surgery. Preoperative and postoperative ophthalmological evaluations included measurement of visual acuity, Hertel exophthalmometry, direct biomicroscopic examination of the cornea and optic disc, and a recording of palpebral fissure height in primary gaze.

\section{Surgical technique}

All patients were operated on by a single surgeon under general anaesthesia using a standardized technique of orbitozygomatic osteotomy in conjunction with three-wall orbital decompression and release of periorbita. Coronal and subtarsal incisions with circumferential dissection of the periorbita provided surgical access to the orbits. A C-shaped osteotomy of the orbitozygomatic complex, extending from the lateral aspect of the supraorbital rim to just lateral to the infraorbital foramen, was performed. The zygomatic arch was osteotomized and the entire orbitozygomatic complex was advanced directly forward an average distance of $8 \mathrm{~mm}$. The remaining lateral orbital wall was removed back to the sphenoid to complete the lateral orbitotomy. Inferior and medial orbital wall orbitotomies were further performed to complete a three-wall orbital decompression. Finally, the periorbita was circumferentially scored using multiple longitudinal incisions, allowing intraconal fat to herniate into the newly expanded orbit. Skeletal stabilization at the osteotomy sites was obtained with rigid internal fixation using miniplates and screws (Figure 1).

\section{Imaging and image analysis}

Preoperative and three-month postoperative computed tomography $(\mathrm{CT})$ scan images were obtained for all patients, using a standardized technique. Scanning was performed on a high speed helical CT scanner with the following technical specifications: $2.5 \mathrm{~mm}$ slices $/ 140 \mathrm{kV} / 180 \mathrm{mAs}$. The data were then transferred to an offline computer workstation (Dell Corporation) and evaluated using Mimics software (Materialise, USA). Using this software, segmentation masks were used to highlight anatomical regions of interest on axial, coronal and saggital images by defining a range of threshold values. These segmentations were done individually for retro-orbital fat, neuromuscular tissue, globe and bony orbit. Contour tracings of these regions were performed on each scan, which were then grown to eliminate noise and separate unconnected structures (Figure 2). Radiological boundaries of the orbit were defined anteriorly by a plane connecting the anterior frontozygomatic process to the nasomaxillary suture and posteriorly by the optic foramen. Linear measurements of ocular globe projection were made from the corneal apex to the lateral orbital rim and to the optic foramen, respectively, and volumetric assessments were then obtained from the two- and three-dimensional images for analysis.

\section{RESULTS}

The clinical, morphological and volumetric outcomes of orbital expansion in severe Graves' exophthalmos were evaluated. Quantitative data pertaining to globe projection and the volumes of intraorbital soft tissue components were used to compare the final results with preoperative data and published 


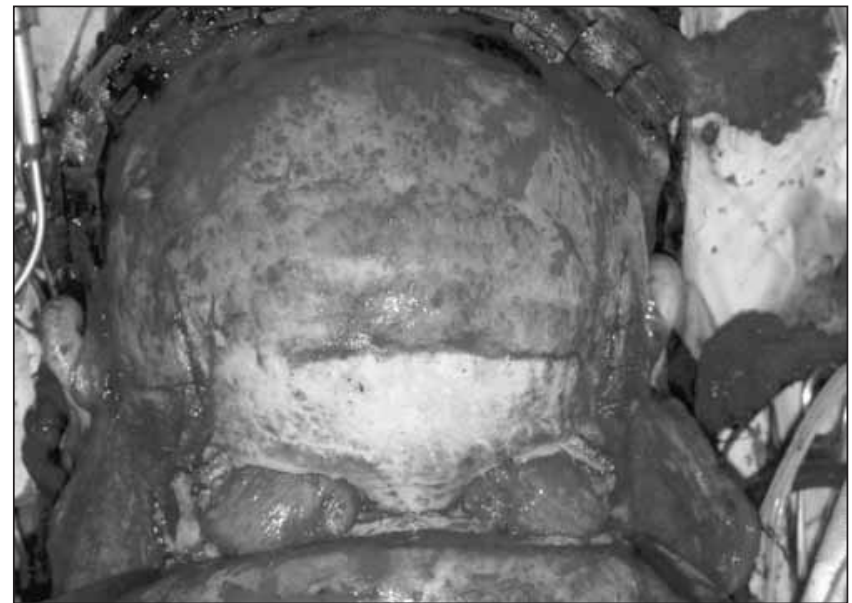

Figure 1) Coronal exposure, showing bilateral orbitozygomatic osteotomy, advancement and fixation

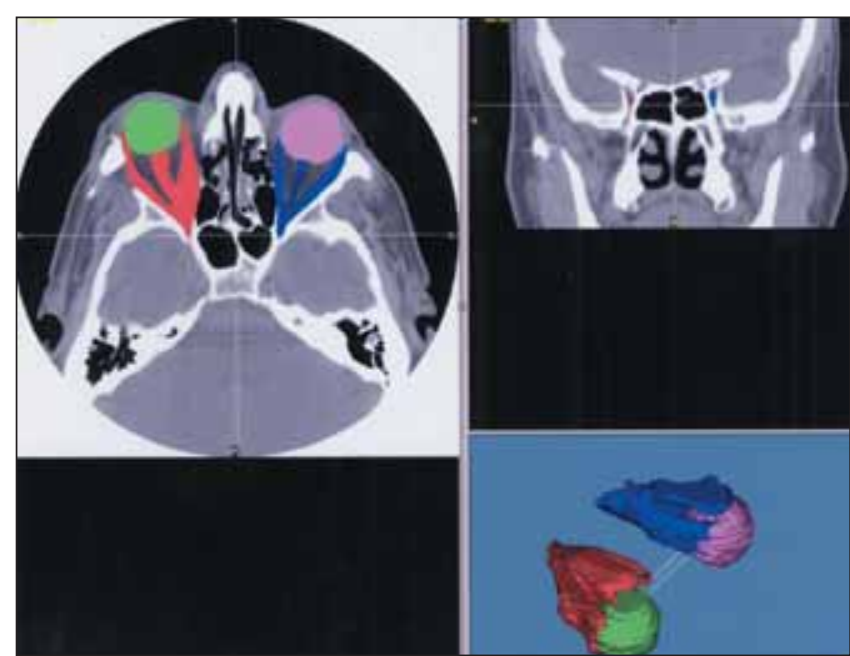

Figure 2) Using Mimics imaging processing software (Materialise, USA), segmentation masks of different thresholds are used to highlight regions of interest on axial, coronal and sagittal computed tomography scan images (including fat, muscle, bone and globe). Linear and volumetric measurements are subsequently made from two- and threedimensional reconstructed images
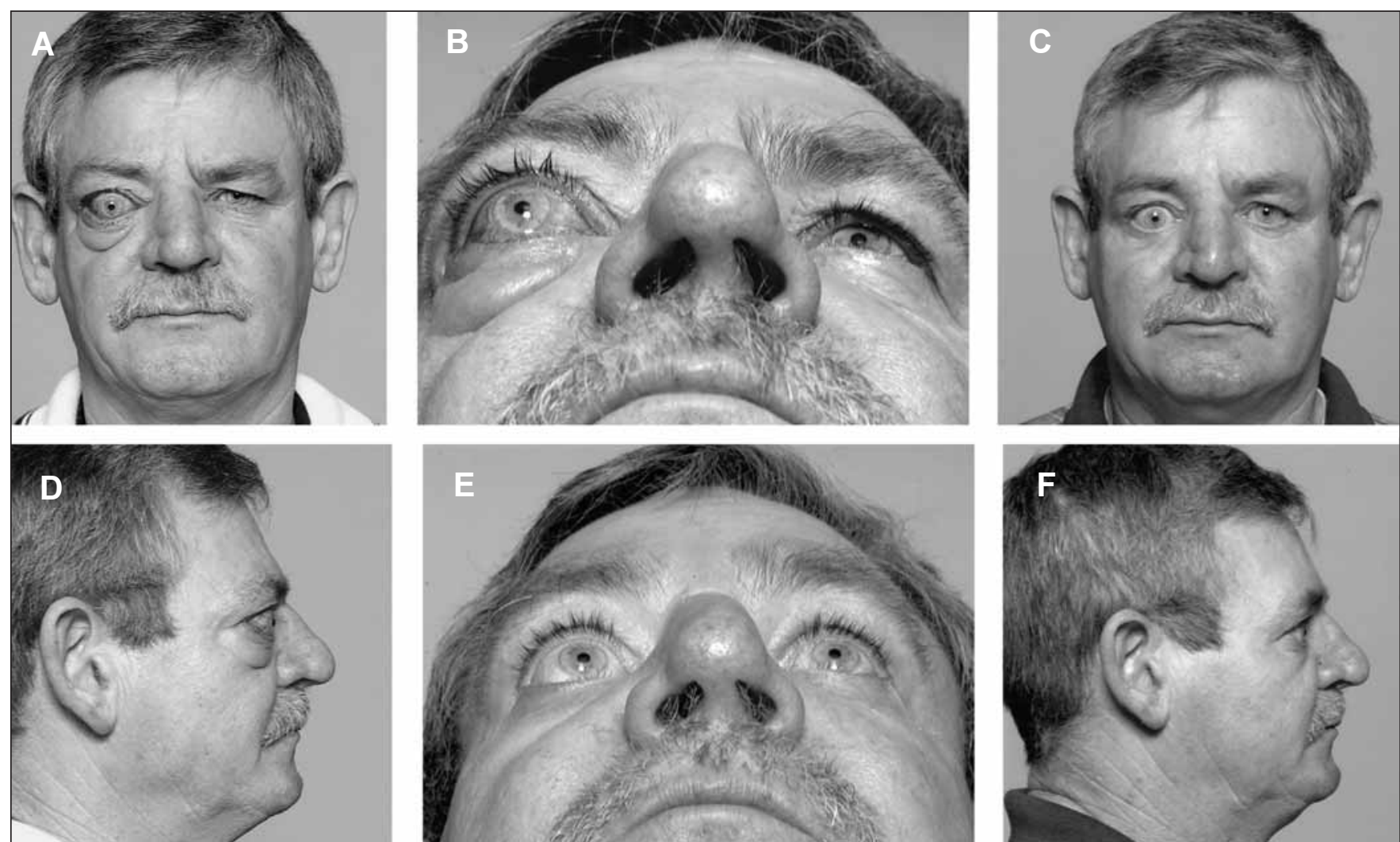

Figure 3) Clinical images demonstrating the reduction in proptosis in a 54-year-old man with severe unilateral exophthalmos. Preoperative photographs (A, B, C). Postoperative photographs (D, E, F). Residual lid retraction will be addressed at a second stage

normative reference data. At three months postoperatively, all patients noted resolution of diplopia, globe pain/pressure and irritative symptoms (Figures 3, 4 and 5).

\section{Ocular projection (Table 1)}

Two separate techniques were used to provide a CT-based determination of ocular projection (Figure 6). Measurement of maximal corneal projection relative to lateral orbital rim is comparable with clinical exophthalmometry, and describes the projection of the ocular globe relative to the orbital aperture. In this series, 3-wall orbital decompression and osteotomy were effective in substantially reducing corneal projection relative to the lateral rim, from a mean of $26.9 \mathrm{~mm}$ to a mean of $20.2 \mathrm{~mm}$ postoperatively. Note that the mean corneal projection of the 

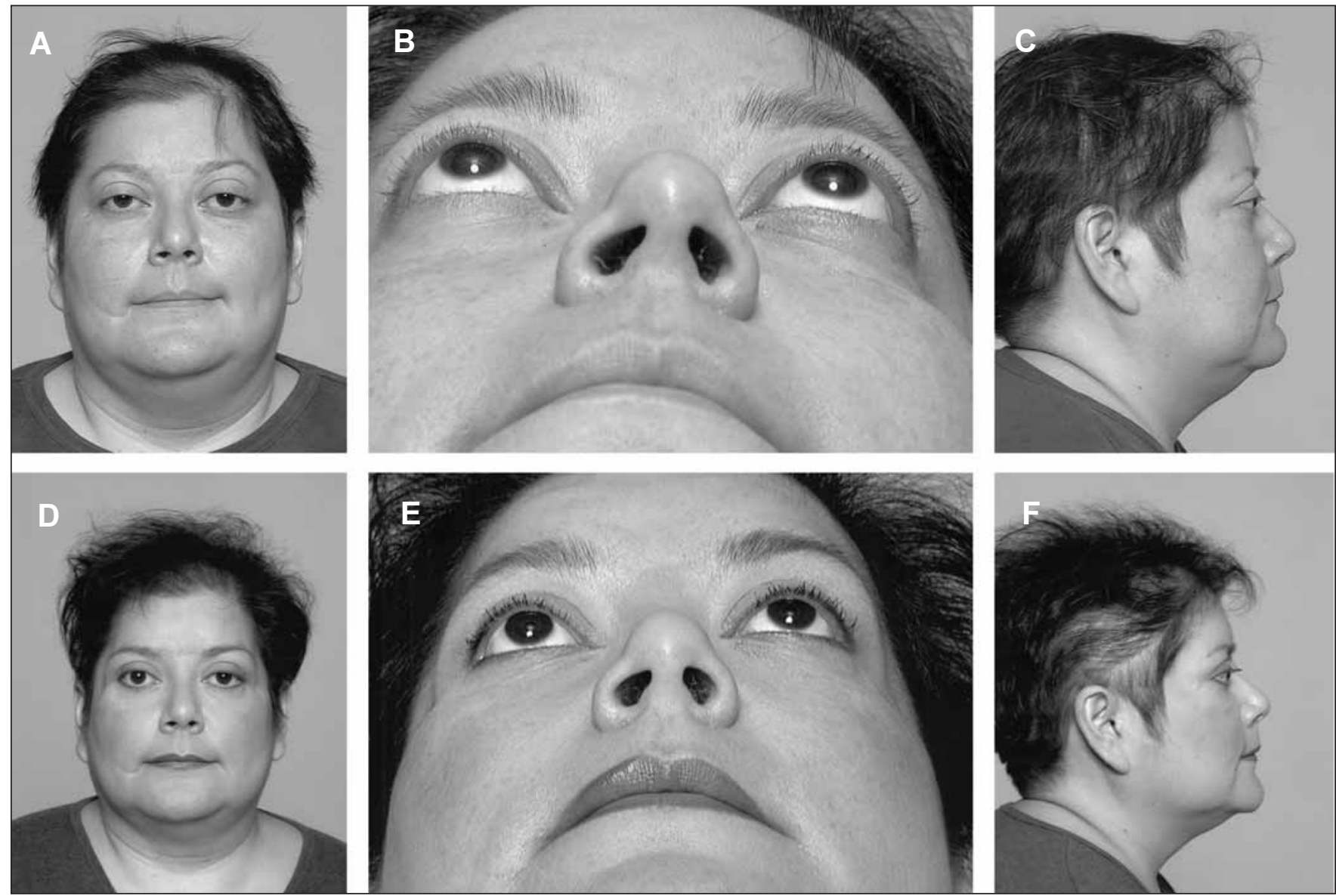

Figure 4) A 40-year-old woman with bilateral exophthalmos. Preoperative photographs (A, B, C). Postoperative photographs (D, E, F)

TABLE 1

Linear measurements of globe projection ( $n=5$ orbits)

\begin{tabular}{|c|c|c|c|c|}
\hline $\begin{array}{l}\text { Corneal } \\
\text { projection }\end{array}$ & $\begin{array}{c}\text { Preoperative } \\
\text { mean }(\mathrm{mm})\end{array}$ & $\begin{array}{c}\text { Postoperative } \\
\text { mean }(\mathrm{mm})\end{array}$ & $\begin{array}{c}\text { Mean retrodis } \\
(\mathrm{mm})\end{array}$ & $\begin{array}{l}\text { olacement } \\
\text { (\%) }\end{array}$ \\
\hline $\begin{array}{r}\text { From lateral } \\
\text { orbital rim }\end{array}$ & 26.9 & 20.2 & 6.7 & 24.9 \\
\hline $\begin{array}{c}\text { From optic } \\
\text { foramen }\end{array}$ & 67.4 & 64.1 & 3.3 & 4.9 \\
\hline
\end{tabular}

lateral orbital rim achieved by decompression was within the upper limit of normal corneal projection (14).

However, orbitozygomatic osteotomy in this series of patients is necessarily associated with the forward translocation of the lateral orbital rim (ie, the reference landmark for standard exophthalmometry is moved forward) (Figure 7). Therefore, globe projection was also measured relative to the optic foramen, a constant skeletal reference unaltered by this surgery. The mean true retrodisplacement of the globe relative to the optic foramen was $3.3 \mathrm{~mm}$.

Orbital volumetric results (Tables 2 and 3)

The C-shaped osteotomy and 3-wall decompression utilized in the reconstruction of each orbit in this series was effective in producing a mean $18.6 \%$ increase in orbital volume. Prolapse of intraorbital soft tissues into orbitotomy defects
TABLE 2

Volumetric measurements ( $n=5$ orbits)

\begin{tabular}{lccc}
\hline Region & $\begin{array}{c}\text { Preoperative mean } \\
\left(\mathbf{m L} / \mathbf{c m}^{\mathbf{3}}\right)\end{array}$ & $\begin{array}{c}\text { Postoperative mean } \\
\left(\mathbf{m L}^{\left.\mathbf{c} \mathbf{c m}^{3}\right)}\right.\end{array}$ & \% difference \\
\hline Bony orbit & 26.6 & 31.6 & 18.6 \\
Orbital fat & 13.3 & 16.4 & 23.4 \\
$\begin{array}{l}\text { Neuromuscular } \\
\text { tissue }\end{array}$ & 10.6 & 11.9 & 12.2 \\
\hline
\end{tabular}

TABLE 3

Normal volumetric measurements

\begin{tabular}{lcc}
\hline Region & \multicolumn{2}{c}{ Mean volume $\left(\mathbf{m L} / \mathrm{cm}^{3}\right)$} \\
Male
\end{tabular}

Data from reference 25

created in the lateral inferior and medial walls was consistently observed.

Volumetric analysis of orbital soft tissues yields completely unanticipated findings. Preoperatively, the volume of fat within the orbit (mean=13.3 mm) in patients with Graves' 

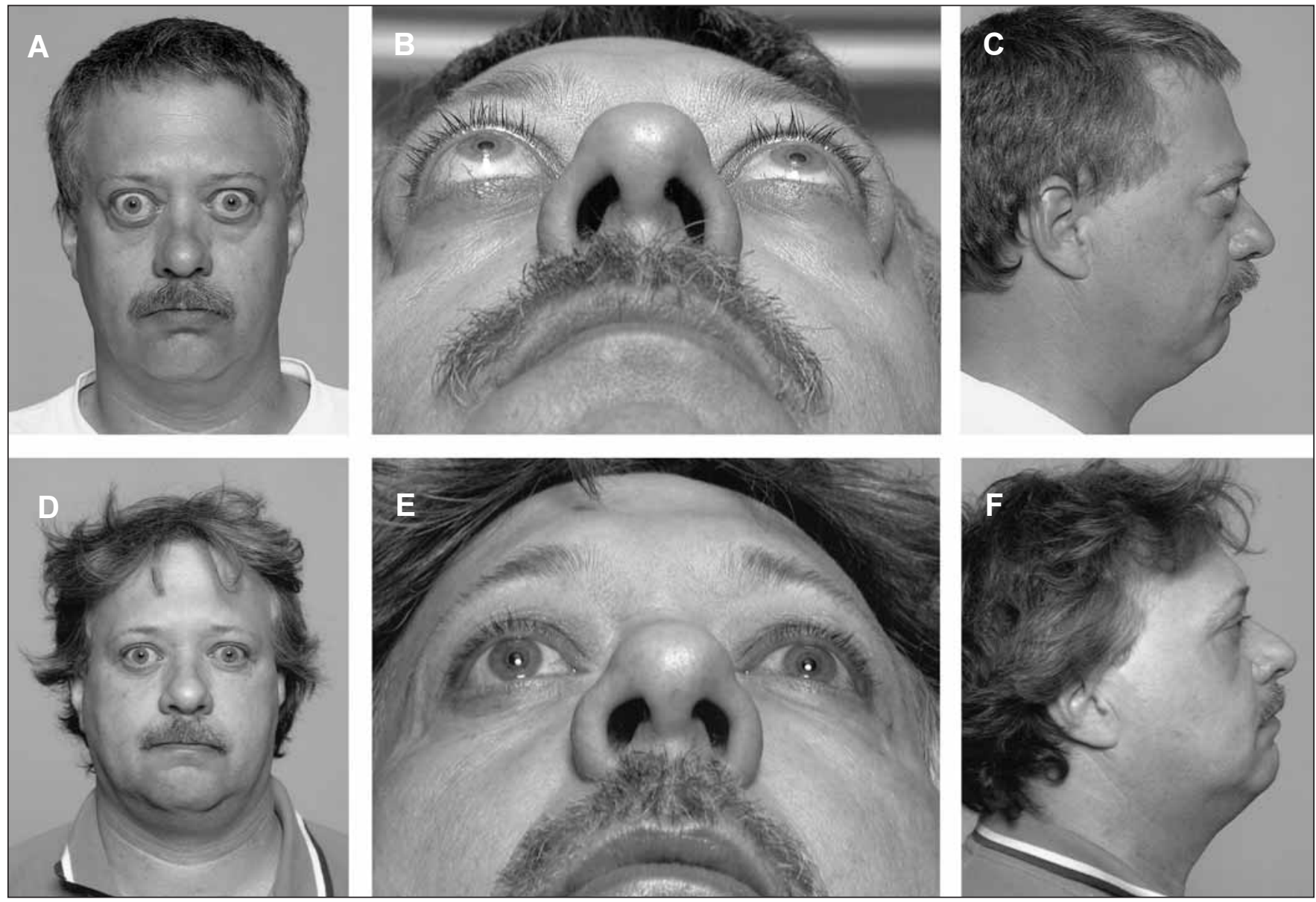

Figure 5) A 40-year-old man with severe bilateral exophthalmos. Preoperative photographs (A, B, C). Postoperative photographs (D, E, F)

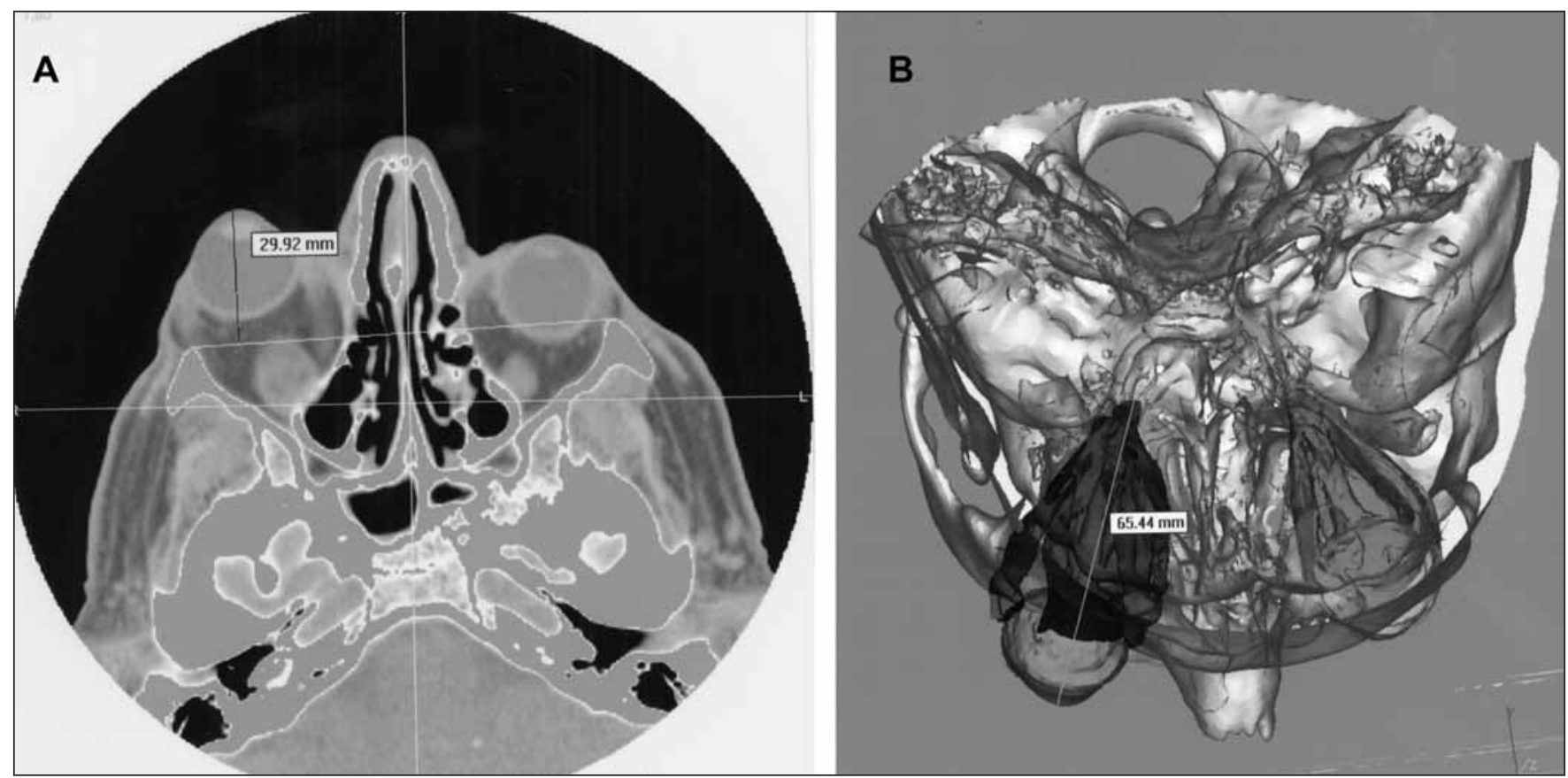

Figure 6) Measurements of globe projection from both the lateral orbital rim (A) and the optic foramen (B) were made from the two-and threedimensional images 

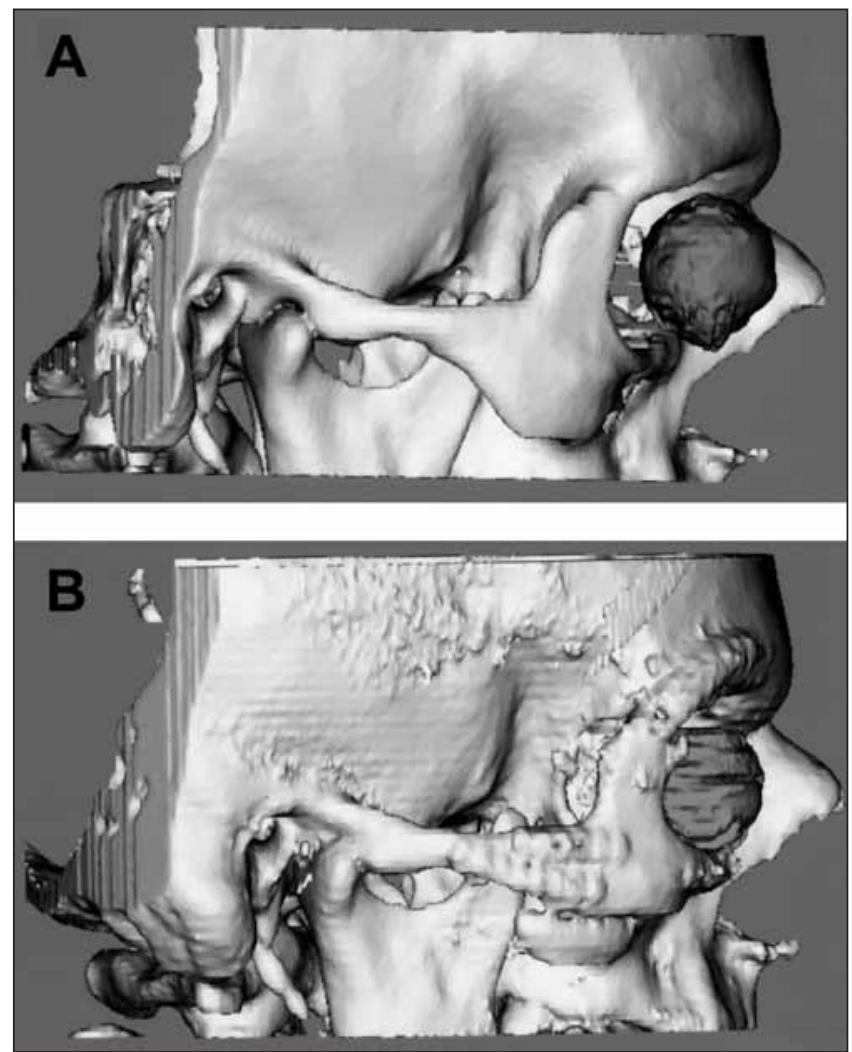

Figure 7) Three-dimensional sagittal view of orbitozygomatic advancement preoperatively (A) and postoperatively (B). Note the reduction in proptosis due to both true globe retrodisplacement into expanded orbit as well as forward translocation of lateral orbital rim

ophthalmopathy was at the upper limit of the normal range, and the volume of neuromuscular tissue (mean=10.6 mL) was substantially greater than normal. Postoperatively, soft tissue volumes actually increased, with a mean $23.4 \%$ increase in fat volume and $12.2 \%$ increase in neuromuscular tissue volume.

\section{DISCUSSION}

Quantitative analysis of orbital cavity and soft tissue volumes based on CT images is a precise and reliable technique which has previously been validated in a cadaver model (1518). CT-based volumetric studies have been used extensively in the investigation of post-traumatic enophthalmos (19-23). These studies have identified a consistent and predictable relationship between ocular projection and orbital volume. Following trauma, the volume of intraorbital soft tissue, including muscle and fat, remains the same. Globe retrodisplacement is directly proportional to the increase in orbital cavity dimensions, ie, for every $1 \mathrm{~mm}$ of enophthalmos there is a $1 \mathrm{~cm}^{3}$ increase in bony orbital volume (24). These findings provide an extremely valuable guide to enophthalmos correction.

This study suggests that the same principle does not apply to patients with Graves' ophthalmopathy. Orbital osteotomy and three-wall decompression produced a mean increase in orbital volume of $4.9 \mathrm{~cm}^{3}$. Assuming the same relationship identified in enophthalmic orbits, one would anticipate a globe retrodisplacement of $4.9 \mathrm{~mm}$. The observed globe retrodisplacement in this population, however, was substantially less (mean=3.3 $\mathrm{mm}$ ).

This can only occur under two circumstances. First, the orbital soft tissues in patients with Graves' ophthalmopathy may not be sufficiently malleable, and may retain preoperative shape rather than fully occupying the space provided by orbital expansion. However, postoperative CT scans consistently demonstrated that this was not the case. Orbital fat did fully prolapse to occupy the entire volume of the expanded orbit. Rather, the resting tone of the extraocular muscles due to varying degrees of fibrosis may be a limiting factor.

Second, the volume of orbital soft tissues may not remain constant. This study does indeed document a consistent and substantial increase in the volume of orbital soft tissues following surgery. Orbital fat volume increased by $23.4 \%$, while neuromuscular tissue increased by $12.2 \%$. This is most likely secondary to cellular infiltrate or edema that is associated with the underlying inflammatory process, or perhaps the surgical procedure itself (25). However, a much larger sample size is necessary to investigate this factor.

\section{CONCLUSIONS}

The characteristic manifestations of Graves' ophthalmopathy have been well-documented by various imaging techniques. However, a correlation between specific operative procedures and the degree of improvement in proptosis has not been well established quantitatively. Using previously validated methods, objective volumetric analysis of involved orbits by offline computer manipulation of their CT scan data was performed. Signals generated from other sources including magnetic resonance imaging may be also used for similar graphic display and volume measurement. It is hoped that when applied to large sample sizes with appropriate controls and extended follow-up, these methods may allow an enhanced understanding of the changes in bony orbital configuration and the subsequent soft tissue response that occur secondary to Graves' orbital surgery. Moreover, a chief goal is that one could eventually determine the relationship of orbitozygomatic advancement to globe retrodisplacement, such that it can be used as an aid in preoperative planning.

\section{REFERENCES}

1. Ginsberg J. Diagnosis and management of Graves' disease. CMAJ 2003;168:575-85

2. Bahn RS, Heufelder AE. Pathogenesis of Graves' ophthalmopathy. N Engl J Med 1993;329:1468-75

3. Wall JR. Graves' disease is a multi-system autoimmune disorder in which extraocular muscle damage and connective tissue inflammation are variable features. Thyroid 2002;12:35-6.

4. Clauser L, Manlio F, Sarti E, Dallera V. Rationale of treatment in Graves' ophthalmopathy. Plast Reconstr Surg 2001;108:1880-94.

5. Gorman CA. Temporal relationship between onset of Graves ophthalmopathy and diagnosis of thryotoxicosis. Mayo Clin Proc 1983;58:515-9.

6. Wolfe SA. Modified three-wall orbital expansion to correct persistent exophthalmos or exorbitism. Plast Reconstr Surg 1979;64:448-55.

7. Olivari N. Transpalpebral decompression of endocrine ophthalmopathy (Graves' disease) by removal of intraorbital fat: Experience with 147 operations over 5 years. Plast Reconstr Surg 1991;87:627-43.

8. Pearl R, Vistnes L, Troxel S. Treatment of exophthalmos. Plast Reconstr Surg 1991;87:236-44.

9. Thaller SR, Kawamoto HK. Surgical correction of exophthalmos secondary to Graves' disease. Plast Reconstr Surg 1990;86:411-21.

10. Kennerdel JS, Maroon JC. An orbital decompression for severe dysthyroid exophthalmos. Opthalmology 1989;89:467-72. 
11. Morax S, Hurbli T. Choice of surgical treatment for Graves' disease. J Craniomaxillofac 1987;15:174-81.

12. Tremolada C, Tremolada MA. The "triple technique" of treating stable Graves' ophthalmopathy. Plast Reconstr Surg 1997;100:40-50.

13. Werner SC. Classification of eye changes of Graves' disease. Am J Ophthalmol 1969;68:646-8.

14. Mercandetti M. Exophthalmos. eMedicine Journal [serial online] 2001; <http://emedicine.com/oph/topic616.htm> (Version current at October 30, 2003)

15. Deveci M, Ozturk S, Sengezer M, Pahuscu Y. Measurement of orbital volume by a 3-dimensional software program: An experimental study. J Oral Maxillofac Surg 2000;58:645-8.

16. Forbes G, Gehring DG, Gorman CA, et al. Volume measurements of normal orbital structures by computed tomographic analysis. AJR Am J Roentgenol 1985;145:149-54.

17. Forbes G, Gorman CA, Gehring D, Baker HL Jr. Computer analysis of orbital fat and muscle volumes in Graves' ophthalmopathy. AJNR Am J Neuroradiol 1983;4:737-40.

18. Forbes G, Gorman CA, Brennan MD, et al. Ophthalmopathy of Graves' disease: Computerized volume measurements of the orbital fat and muscle. AJNR Am J Neuroradiol 1986;7:651-6.

19. Bite U, Jackson IT, Forbes G, et al. Orbital volume measurement in enophthalmos using three-dimensional CT imaging. Plast Reconstr Surg 1985;75:502-8.

20. Jin HJ, Shin S, Choo M, Choi Y. Relationship between the extent of fracture and the degree of enophthalmos in isolated blowout fractures of the medial orbital wall. J Oral Maxillofac Surg 2000;58:617-20.

21. Raskin E, Milman A, Lubkin V, et al. Prediction of late enophthalmos by volumetric analysis of orbital fractures. Ophthal Plast Reconstr Surg 1998;4:19-26.

22. Ploder O, Klug C, Voracek M, et al. Evaluation of computer-based area and volume measurement from coronal computed tomography scans in isolated blowout fractures of the orbital floor. J Oral Maxillofac Surg 2002;60:1267-72.

23. Dolynychuk K, Tajdalle H, Manson P. Orbital volumetric analysis: Clinical application in orbitozygomatic injuries. J Craniomaxillofac Trauma 1996;2:56-63.

24. Manson PN, Grivas A, Rosenbaum A, et al. Studies on enophthalmos: II. The measurement of orbital injuries and their treatment by quantitative computed tomography. Plast Reconstr Surg 1986;77:203-14.

25. Wilson WB, Manke WF. Orbital decompression in Grave's disease: The predictability of reduction of proptosis. Arch Ophthalmol 1991;109:343-5. 